\title{
EL DERECHO A PARTICIPAR EN LA VIDA \\ CULTURAL Y SUS CONSECUENCIAS PARA \\ EL APRENDIZAJE: UNA HISTORIA DE VIDA
}

\author{
The right to participate in cultural life and its consequences \\ for learning: a life story
}

\section{Tomàs Segarra Arnau \\ Departament d'Educació, Universitat Jaume I}

RESUMEN: El trabajo que se presenta es una síntesis de una investigación sobre la participación en la vida cultural, que tiene como objetivos incidir en aquello que motiva su desarrollo y conocer los aprendizajes que se derivan del mismo. La investigación se ha llevado a cabo partiendo del enfoque biográfico-narrativo, mediante algunas de las herramientas que le son propias: el biograma, la entrevista biográfica y el uso de fuentes documentales. El principal resultado de la investigación es la historia de vida de Jaime, una persona que vive en una pequeña población de la provincia de Castellón, muy implicada en los procesos de participación en la vida cultural de su municipio, tanto desde el mundo asociativo como desde el institucional. Las conclusiones destacan que los aprendizajes relacionados con la participación en la vida cultural se manifiestan en las cuestiones de la identidad cultural y de la convivencia, en el concepto de ciudadanía activa y en la institucionalización de la cultura.

Palabras clave: derechos culturales, investigación biográfica-narrativa, ciudadanía activa, identidad cultural, institucionalización de la cultura.

RESUM: El treball que es presenta és una síntesi d'una recerca sobre la participació en la vida cultural, que té com a objectius incidir en el que motiva el seu desenvolupament $i$ conèixer els aprenentatges que es deriven del mateix. La recerca s'ha dut a terme partint de l'enfocament biograficonarratiu, mitjançant algunes de les eines que li són pròpies: el biograma, l'entrevista biogràfica i l'ús de fonts documentals. El principal resultat de la investigació és 
la història de vida de Jaume, una persona que viu en una xicoteta població de la província de Castelló, molt implicada en els processos de participació en la vida cultural del seu municipi, tant des del món associatiu com des l'institucional. Les conclusions destaquen que els aprenentatges relacionats amb la participació en la vida cultural es manifesten en les qüestions de la identitat cultural i de la convivència, en el concepte de ciutadania activa i en la institucionalització de la cultura.

Paraules clau: drets culturals, investigació biograficonarrativa, ciutadania activa, identitat cultural, institucionalització de la cultura.

ABSTRACT: This paper summarizes a study on participation in cultural life which aimed to learn what motivates its development and the knowledge that derives from it. This research followed a narrative-biographical approach using biograms, biographic interviews and documentary sources. The main result of the investigation is the life story of Jaime, a resident in a small town in the province of Castellón, who is deeply involved in the participative processes of local cultural life in the town's associations and institutions. The conclusions highlight how learning related to participation in cultural life is reflected in issues of cultural identity and coexistence, active citizenship and the institutionalization of culture.

KEYWORDS: cultural rights, narrative-biographical research, active citizenship, cultural identity, institutionalization of culture.

\section{Introducción}

El presente artículo es una síntesis de mi Trabajo de Final de Máster en Gestión Cultural (Segarra, 2013), una investigación sobre la participación en la vida cultural, a través de la historia de vida de una persona muy implicada en este tipo de procesos. La relevancia del estudio viene dada porque la participación en la vida cultural es una categoría de los derechos humanos que no 
ha sido todavía suficientemente desarrollada ni aplicada (Arroyo, 2006). Al plantear el estado de la cuestión, me encontré con que el número de trabajos sobre esta temática, desde un enfoque cualitativo, era escaso. Esto me llevó a plantearme qué podía aportar la investigación cualitativa a este ámbito de estudio.

Los objetivos del trabajo, planteados a partir de las preguntas de investigación, son establecer los motivos por los que se participa en la vida cultural desde los posicionamientos más activos, y los aprendizajes que se derivan del mismo. Desde el punto de vista metodológico, en la investigación he utilizado el enfoque biográfico-narrativo, que generó una única historia de vida. Empleé como herramientas metodológicas el biograma y la entrevista biográfica. También tuve acceso a fuentes documentales relacionadas con la vida de la persona investigada.

El resultado de la investigación es la propia historia de vida de Jaime, una persona que, a lo largo de su vida, se ha implicado de forma muy activa en procesos de participación en la vida cultural. En este artículo presento los aspectos más destacados de esa historia en base a los diversos espacios para la participación y, especialmente, a los ámbitos asociativo e institucional.

A partir de los resultados, he articulado las conclusiones y la discusión final. Destaco aquí los aspectos relacionados con el aprendizaje sobre la propia identidad y la convivencia, sobre el concepto de ciudadanía activa y, finalmente, sobre la institucionalización de la participación en la vida cultural.

\section{La participación en la vida cultural}

La participación en la vida cultural es todavía hoy una categoría poco investigada y poco desarrollada, que apareció por primera vez en el artículo 27.1 de la Declaración Universal de Derechos Humanos de las Naciones Unidas, de 1948: «toda persona tiene derecho a tomar parte libremente en la vida cultural de la comunidad, a disfrutar de las artes y a participar en el progreso científico y en los beneficios que de él resultan». 
Aunque han pasado ya casi 70 años desde la Declaración, los derechos culturales son todavía hoy los grandes olvidados del constitucionalismo moderno. Su presencia en las cartas magnas de los diferentes países es testimonial (Arroyo, 2006). La resolución del debate sobre los derechos culturales, entendidos como la norma de acceso al espacio de la cultura en condiciones de igualdad, todavía está lejana. Para Laaksonen (2006) hay que buscar las causas en el hecho de que este tipo de derechos son capaces de reunir elementos que pocas veces comparten espacios comunes: arte, cultura, derecho y política (Laaksonen, 2006).

De hecho, la definición de los derechos culturales es una tarea que todavía se está llevando a cabo en nuestros días, siendo la Declaración de Friburgo (Grupo de Friburgo, 2007) uno de los documentos que más se ha destacado en este sentido en los últimos años. Se trata, así pues, de la categoría menos desarrollada de derechos humanos en cuanto a su contenido legal y a la obligatoriedad de su cumplimiento. Según Achugar (2003) entre los motivos de esta falta de desarrollo se encuentran las tensiones entre políticas e ideologías, entre lo local y lo global, entre el individuo y lo colectivo y, finalmente, entre la universalidad de la cultura y el relativismo cultural.

Los derechos culturales comprenden el derecho a la identidad cultural, a la participación en la vida cultural, a la conservación y difusión de la cultura, a la protección de la propiedad cultural, y los derechos de creadores, intérpretes y artistas (Laaksonen, 2006).

En los años 80, la Declaración de Bremen circunscribió la acción participativa en la vida cultural a algo que sucede en el ámbito local. Al mismo tiempo, entendió que se trataba de un proceso básico para el desarrollo democrático, ya fuese desde posicionamientos pasivos (participación en eventos) o activos (participación en procesos decisorios).

En la actualidad se tiende a considerar que la participación en la vida cultural dota de mayor sentido a la cohesión social y al desarrollo de unos valores comunes. Esto contribuye al empoderamiento de aquellas comunidades que ponen en funcionamiento mecanismos de participación (Segarra, 2013). Tomar parte, o participar, en la vida cultural de una comunidad es el resultado de una triple dimensión: participar, acceder y contribuir (Shaheed, 2010). 
Participar implica el derecho a actuar libremente, a escoger la propia identidad, a ejercer las prácticas culturales propias, a expresarse en la lengua que se escoja libremente y a actuar y tomar parte en actividades culturales.

El acceso a la vida cultural se define como el derecho de las personas a conocer y entender la cultura propia y la de los demás mediante la educación y la información, a utilizar los bienes culturales, y a beneficiarse del patrimonio cultural y de las creaciones de los demás.

La contribución a la vida cultural se refiere a la creación de las manifestaciones de la propia cultura, al derecho a participar en el desarrollo de la comunidad de pertenencia y a la definición, formulación y aplicación de políticas y decisiones relativas a sus derechos culturales.

En este último sentido, según Pascual, Dragojević y Dietachmair (2007), la participación ciudadana en las políticas públicas locales es la respuesta a algunas de las cuestiones que plantea el mundo actual y donde la cultura tiene algunas cosas que decir: la garantía de los derechos humanos, la sostenibilidad, los retos entre lo local y lo global, y la diversidad. Con ellos coinciden Francés, García y Santacreu (2007), para quienes la participación es una finalidad socialmente deseable, y a la que se debe aspirar como esencia democrática. Estos autores también argumentan que la participación es una herramienta para afrontar los retos de una sociedad cada vez más compleja, caracterizada por el rápido cambio social, las limitaciones de la actividad institucional, la aparición de nuevos problemas sociales, y la incertidumbre ligada al proceso de mundialización en las prácticas culturales.

La participación puede ser más o menos activa y empoderadora. Para Gadea (2007) los mecanismos para tomar parte transitan desde los pasivos, de carácter informativo, pasando por los consultivos, hasta llegar a los mecanismos más activos que permiten la intervención de la ciudadanía en la toma de decisiones.

Desde el punto de vista de las experiencias que conectan participación y gobierno local, Pindado, Rebollo y Martí (2002) describen dos vías: la participación como legitimación de las políticas, o como un proceso fundamental que busca la transformación social. Para estos autores la vía transformadora de la participación es un proceso educativo donde las personas se convierten 
en el principal instrumento. Más allá de la creación de reglamentos o de organismos para la participación, consideran que ésta se ha de construir sobre la base de unas nuevas formas de actuar, y de unas nuevas relaciones entre la administración y la ciudadanía donde puedan trabajar conjuntamente políticos, técnicos y ciudadanía.

Desde el punto de vista de la educación, la participación en la vida cultural se relaciona con el aprendizaje a lo largo de la vida. En un mundo en constante cambio, educarse continuamente es indispensable para afrontar el siglo XXI (Delors, 1996). Surge así un nuevo concepto de educación que no se limita a la dimensión cognitiva —enseñanza-aprendizaje - del conocimiento (Merino, 2011). Por contra, este nuevo concepto da valor a los aspectos éticos y culturales (Ortega, 2005) para construir un individuo que es, hace, aprende y convive. Esto nos lleva a identificarnos como seres que aprendemos y como participantes activos de nuestro propio aprendizaje (Ramdsen, 1992).

A través de una investigación de carácter biográfico narrativo, y en relación con el ámbito de la participación en la vida cultural, me marqué las siguientes preguntas de investigación:

1. ¿Por qué se participa en la vida cultural desde los posicionamientos más activos?

2. ¿Qué relaciones existen entre la participación en la vida cultural y la educación a través de procesos de aprendizaje informal?

\section{Metodología}

Consideré que la investigación biográfico-narrativa podía ser una metodología adecuada para esta disciplina de estudio. El motivo principal fue que el relato biográfico da voz a los sin voz. En este caso concreto, los estudios que tratan los derechos culturales ignoran a menudo a la población en tanto que agente cultural (Martinell y López, 2008; Moriña, 2010). La investigación de la participación cultural implica la medida y la comprensión, y por tanto el uso de metodologías tanto cuantitativas como cualitativas, de cualquier actividad que suponga un incremento de las capacidades y del capital cultural 
e informacional de las personas, y que contribuyan a definir sus identidades (UIS, 2012). Medir la participación es difícil (Sáez, 2012). Desde un punto de vista pasivo, asistir a un concierto o visitar una exposición ya implica participar. Sin embargo, cuando nos acercamos a forma de participación más activa, ¿qué es lo que podemos investigar?

El enfoque cualitativo contribuye a la comprensión de problemas de mayor complejidad: hábitos, conducta, actitud de las personas, etc. Contribuyen a mejorar las posibilidades de interpretar los fenómenos relativos al compromiso y a la participación cultural. Así, la investigación cualitativa, se convierte en una herramienta adecuada para el estudio de los procesos activos de participación en la vida cultural (Segarra, 2013).

A través de la estructura narrativa, las personas dotan de sentido a su mundo. En consecuencia, la narrativa tiene la función de proporcionar a las personas formas de interpretación, y guías para la acción. La narración organiza, así, la experiencia humana a través de un proceso de reconstrucción, pero no de una representación de la realidad. No se trata de dar a conocer los hechos tal como sucedieron, sino de saber cómo el narrador da sentido a su propia experiencia (Bolívar, Domingo y Fernández, 2001).

Dado que el conocimiento se construye desde un posicionamiento compartido, nunca desde el punto de vista único del investigador (Kreusburg, 2011), el compromiso ético de éste es doble. Por un lado, con las experiencias de las personas que narran sus historias y, por otro, con las formas en las que estas experiencias son contadas. Al mismo tiempo, el investigador ha de ser consciente de que, a través de su papel, ejerce influencias en el narrador, como observador que es, y de que tiene el reto ético de mover los contextos narrados hacia situaciones de mayor dignidad.

Para la selección de la muestra partí del ideal de la ciudadanía activa, con un interés público, por acercarse al modelo propio de ciertas concepciones del republicanismo y de la democracia radical (Gadea, 2007). Se trata de un actor que no sólo discute y debate. También participa en el proceso sociopolítico. Este último perfil era el más interesante a la hora de concretar la muestra, dado que partía de la hipótesis de que determinadas personas se implican de forma más activa en la vida cultural, mediante asociaciones u organismos de participación ciudadana. En el caso de las poblaciones del medio rural, estos condicionantes 
se acentúan. Algunas personas son capaces de dinamizar procesos, formar parte de asociaciones, implicar a otras personas, etc.

Construí la investigación a partir del relato de Jaime, auxiliar administrativo en un ayuntamiento de una localidad del medio rural de la provincia de Castellón, de unos 2.000 habitantes. A lo largo de su vida, Jaime ha sido una persona íntimamente ligada a la cultura y a la protección y difusión del patrimonio histórico de su localidad, tanto a título individual como a través de su participación en el mundo asociativo, y a su trabajo desde la administración pública.

Las herramientas que utilicé para la investigación fueron el biograma y la entrevista biográfica. También tuve acceso a fuentes documentales, especialmente actas de algunas de las asociaciones en las que ha participado Jaime a lo largo de su vida. Aproveché estos documentos, especialmente, para situar cronológicamente los acontecimientos que él mismo refiere.

El biograma facilitó una reflexión retrospectiva inicial sobre la vida de Jaime. Consistió en la elaboración de una tabla que combinaba acontecimientos, valoración de los mismos en algunos casos, y una cronología aproximada (Bolívar et al., 2001).

A partir del biograma, inicié la confección del cuestionario para la entrevista biográfica, base de esta metodología. Conté con la colaboración del mismo Jaime para perfilar, tanto como fue posible, el listado de preguntas. En consecuencia, realizamos diversos borradores previos antes de cerrar el cuestionario definitivo.

El cuestionario quedó articulado en base a cinco ejes, cada uno de ellos correspondiente a las diversas fases y ámbitos de la vida cultural y educativa de Jaime, más un último bloque que giraba alrededor del concepto de participación en la vida cultural. Este último bloque fue incluido para profundizar en diversos aspectos de la participación (participación, acceso y creación/ producción), y lanzar una proyección de futuro basada en la reflexión sobre estos aspectos. En conjunto, se trataba de una entrevista muy focalizada, que buscaba incidir en aquellos aspectos que más interesaban de cara a la investigación. 
El cuestionario comenzaba con un primer bloque de preguntas de carácter general, que ayudaba a construir el marco a través del cual iba a transcurrir la entrevista. Este primer bloque se completaba con dos apartados más, vinculados a los ámbitos educativos por los que transcurrió la vida de Jaime durante su infancia y adolescencia. De este modo se profundizaba en los ámbitos de socialización secundaria de Jaime, con especial énfasis en los espacios de aprendizaje fuera de la escuela.

Un segundo bloque incidía a incidir en el acceso de Jaime al mundo laboral y a las tareas que lleva a cabo en su puesto de trabajo. Este bloque era importante porque Jaime ha desarrollado toda su carrera profesional en el ayuntamiento de su localidad, un espacio desde el que se ha podido sumergir en la vida comunitaria y en el desarrollo democrático de la sociedad local.

El tercer bloque, más amplio, suponía un recorrido por la vida de Jaime desde el punto de vista de su implicación en diversas asociaciones existentes en la localidad: la banda de música, la asociación juvenil, la Cruz Roja, la rondalla, etc. Además, dentro de este bloque se dedicaba un último apartado para valorar la relación de Jaime con el mundo asociativo en su conjunto.

La cuarta parte del cuestionario se centraba en el Patronato de Cultura de la localidad, del que Jaime ha formado parte activa desde su creación. Los apartados de este bloque hacían referencia a la creación del organismo, la dinámica interna de trabajo, la actividad que lleva a cabo, su utilidad y, finalmente, a los saberes que Jaime ha adquirido a través de su implicación. Era el bloque más importante de la entrevista, dado que el Patronato de Cultura era el espacio desde el que Jaime participaba de forma más activa en la vida cultural de la población. Esto es debido a que este organismo se encargó, durante dos décadas, de planificar y llevar a cabo las políticas culturales locales.

El quinto bloque trataba de la relación de Jaime con el Programa de Extensión Universitaria de la Universitat Jaume I. Este programa, desde su creación, trabaja conjuntamente con las poblaciones de menos de 5000 habitantes de las comarcas de Castellón, en materia formativa y cultural.

En suma, el tercer bloque estaba dedicado a la participación cultural desde los puntos de vista del acceso y la creación/producción, mientras que el cuarto 
y el quinto se centraban en la participación en organismos donde se toman decisiones referentes a la cultura.

En la última parte, llevábamos a cabo un ejercicio de valoración y de reflexión sobre todo lo dicho, y también de proyección acerca de los tres aspectos que forman parte del derecho a la participación cultural: acceso, creación y participación.

Realizamos cinco sesiones de entrevista, a lo largo de dos semanas, para un total de cinco horas y media de grabación. Grabé todas las sesiones en vídeo, y transcribí su contenido posteriormente. Finalmente, decidí mantener el anonimato de las terceras personas que aparecían en la entrevista (Bolívar, 2002) y solicité por escrito a Jaime su consentimiento informado en referencia al uso que se daría al material de la entrevista.

En cuanto al análisis de los datos, en la elaboración del relato tuve en cuenta los cuatro inconvenientes identificados por Leite (2011), cuya superación contribuye a dar coherencia y validez a la investigación: fidelidad, reconstrucción de la historia de vida, superación de la ordenación cronológica, y reducción de la historia de vida a una interpretación de la misma.

\section{Análisis de resultados}

El análisis de los resultados de la investigación se presentó como una única historia de vida. Se trata de un relato compartido y construido conjuntamente entre el narrador y el investigador, de acuerdo con los principios metodológicos del enfoque biográfico-narrativo. En consecuencia, en este apartado presento una síntesis de los resultados estructurados a modo de resumen de la historia de vida de Jaime. Se sigue, fundamentalmente, un hilo cronológico de los acontecimientos que transita por los espacios de socialización durante la infancia, la participación en movimientos asociativos, y la participación en instituciones culturales. La historia de vida concluye con un conjunto de reflexiones sobre los aprendizajes adquiridos a lo largo de este camino.

Jaime nació y ha vivido siempre en una población del interior rural de la provincia de Castellón. Trabaja en el ayuntamiento de su localidad desde los 
18 años. En el momento de la entrevista tenía 50. Se encuentra muy unido a su población y, sobre todo, a su gente. A ellos ha dedicado gran parte de su trabajo, dentro y fuera de su horario laboral. Una actividad sin la que, afirma, no sería la misma persona. Trabajar para los demás le ha llenado, y le sigue llenando como pocas cosas en la vida.

La infancia de Jaime transcurrió en la escuela, en la parroquia y en las calles de la población. De sus primeros maestros, Jaime destaca a uno que, por escapar de las metodologías tradicionales, le marcó especialmente:

Era un maestro que nos comenzó a hacer salir por la calle, por el término [municipal], a ver cosas, íbamos a buscar fósiles, nos hacía alguna excursioncita por el término y nos enseñaba la naturaleza.

La calle era el espacio de juegos por excelencia. Al salir de la escuela, a las cinco de la tarde, los niños y niñas jugaban en diversas plazas de la población. En una de ellas, cerca de su casa, se dedicaban a imitar a los mayores: jugaban a toros y reproducían las fiestas patronales. También se inventaban juegos, y se divertían con los más tradicionales. Cualquier actividad, como dar vueltas a una fuente, se podía convertir en un juego. Durante el verano, los hijos de los emigrantes que volvían para pasar las vacaciones, hacían las tardes todavía más divertidas. Se vivía en la calle, o se juntaban diversas familias del vecindario para ver la televisión, que acababa de llegar al pueblo.

En la parroquia, Jaime colaboró como monaguillo durante muchos años. Considera que esto le hizo crecer de forma diferente al resto de personas de su generación. Ser monaguillo le comportaba inconvenientes, como no disponer de tiempo para la práctica de algún deporte, pero también ventajas de cara a su formación: en él se despertó un interés precoz por la cultura y el patrimonio. En ello influyó el párroco, que emprendió la creación de un museo. La iglesia del pueblo, que goza de la declaración de monumento nacional, no había sido objeto de mucha atención hasta aquel momento. Aquel cura, además de promover el museo, fue el primero en empezar a ejercer como guía para los cada vez más habituales visitantes. Jaime solía escuchar aquellas explicaciones con mucha atención. En algunas ocasiones, cuando el cura no estaba, era él quien llevaba a cabo las visitas. También abría y cerraba la iglesia. Tenía ocho o nueve años. 
Jaime considera que su inquietud por la cultura y el patrimonio locales nacieron en aquella época. Siguió haciendo visitas guiadas a lo largo de los años. Se documentaba por su cuenta y también aprendía de lo que escuchaba:

De lo que escuchaba, de cómo lo explicaban, fui haciéndome un esquema mental. Dije «pues primero explicaré la portada, después explicaré la iglesia, el museo...» Después comencé a leer cómo se hicieron Cortes Generales [en la población], hubo maestres [de órdenes de caballería] que se enterraron aquí, y poco a poco fui recopilando más información.

Para poder cursar estudios de bachillerato, Jaime tuvo que desplazarse diariamente a un municipio más grande. Más adelante, dado que su rendimiento académico no era bueno, decidió pasarse a la rama de mecánica de formación profesional. En esa etapa, un hecho le marcó profundamente, y reforzó sus ideas a propósito de la defensa del patrimonio. Se trata de la destrucción de los hornos medievales de la población, del siglo XIv:

Recuerdo que pasé por allí y vi el horno derruido, con los arcos en pie. Y claro, no se podía hacer nada porque todo esto del patrimonio no pintaba nada. $\mathrm{Y}$ al día siguiente lo vi todo derruido, todos los arcos derruidos. Esto me dolió muchísimo, ¡mucho! ¡Me afectó muchísimo! Particularmente, me afectó como diciendo «¿Cómo pueden destruir todo esto?» Y de aquí, pues bien, han venido un poco las inquietudes en el tema patrimonial.

Jaime encontró en su profesor de historia y en un abogado de la población a dos interlocutores con los que hablar sobre el patrimonio y la historia de la localidad. La gente de su generación, en cambio, tenía pocas inquietudes en este sentido.

Desde muy joven, Jaime se implicó activamente en el movimiento asociativo de su localidad. La primera entidad de la que formó parte, fue el grupo de danzas. En ella participó primero bailando y más adelante cantando. Todavía siendo un niño de nueve o diez años, formar parte de esta asociación le permitía visitar otras poblaciones con asiduidad.

Jaime se define como una persona alegre a la que le gusta mucho la música. Siempre está silbando y canturreando. A principios de los años 80, cuando contaba con 16 o 17 años, le invitaron a formar parte de la banda de música de la localidad. Les faltaba un percusionista. De este modo, Jaime 
empezó a estudiar solfeo y a tocar la caja. Todavía hoy en día forma parte de esta agrupación.

En 1982 dejó los estudios de formación profesional para centrarse en unas oposiciones a auxiliar administrativo, convocadas por el ayuntamiento de su población. Tras aprobarlas, comenzó a trabajar en el consistorio realizando las tareas más básicas y ayudando a sus compañeros. Aquel mismo año se creó un museo municipal con piezas propias del ayuntamiento, otras cedidas por la Diputación de Castellón, y donaciones de los vecinos del pueblo. Se creó una junta y Jaime, con 20 años, fue designado director, tarea que debía compatibilizar con las demás que llevaba a cabo en el ayuntamiento.

Meses después, se marchó a Alicante para llevar a cabo el servicio militar. Pasado el tiempo de la instrucción, volvió a su población para completar, en la Cruz Roja, la «mili», tarea que compaginó con su trabajo en el ayuntamiento. Una vez finalizado el servicio, decidió seguir vinculado a esta institución como voluntario. En 1984 fue nombrado secretario de la asamblea de la Cruz Roja local. Los cargos y responsabilidades crecieron rápidamente hasta llegar a ser, durante 16 años, vicepresidente provincial. Actualmente también es miembro de la Asamblea Nacional de Cruz Roja. Pero más allá de los cargos directivos, para Jaime es la tarea de voluntario la que le ha llenado personalmente, por lo que comporta en cuanto a trabajo humanitario y por el hecho de poder ayudar a quien lo necesita.

Al mismo tiempo, también se involucró en la asociación juvenil. En 1981 entró a formar parte de la junta como tesorero. En 1985 fue elegido presidente, cargo que ocupó hasta 1991. La asociación se encargaba, principalmente, de dar opciones de ocio a la juventud de la localidad. Se organizaban bailes los fines de semana y verbenas durante las fiestas patronales. A partir de 1987 la directiva decidió comenzar a programar, precisamente durante las fiestas, la actuación de un grupo de música pop de nivel nacional. Los primeros en pasar por la población fueron Olé Olé, a los que siguieron Gabinete Caligari, Loquillo y los Trogloditas, Ramoncín...

La sociedad, sin embargo, no disponía de un espacio en condiciones donde llevar a cabo estas actuaciones. Del solar de un antiguo molino harinero que se quedó pequeño, se pasó al patio de la escuela. Finalmente, se decidió crear un local en el que poder llevar a cabo las actuaciones: el polideportivo. El 
ayuntamiento se comprometió a pagar el material, y la asociación juvenil puso la mano de obra mediante el sistema de jornal de vila. Este sistema tradicional de la zona consiste en la aportación de horas de trabajo por parte de toda la comunidad para la construcción de una obra pública. No se había utilizado en la población desde los tiempos de la posguerra.

Por otro lado, durante los años en los que Jaime presidió la sociedad juvenil, ésta se organizó en comisiones que permitieron realizar actividades culturales distintas a las habituales: una revista, la convocatoria de unos premios de investigación, viajes, una acampada de verano para los niños y niñas del pueblo, y un espectáculo teatral durante las fiestas patronales, organizado y protagonizado por los mismos jóvenes. Debido a esta ampliación de la actividad, fue necesario comenzar a solicitar subvenciones a la Diputación de Castellón y a la Conselleria de Cultura del Gobierno Valenciano, aunque desde estas instituciones no siempre se valoraba el trabajo que realizaba la asociación de un modo positivo:

Solicitábamos las ayudas, y nos excluyeron porque determinadas cosas no las consideraban cultura. Hice una nota de prensa en el periódico quejándome [...] de que no entendían eso como cultura y nos habían denegado la subvención.

También en la banda de música ocupó la presidencia algunos años. Durante su etapa se preocupó por fomentar la realización de intercambios con otras bandas, como forma de abrir y cohesionar la asociación. Al mismo tiempo, también trabajó para la creación de una escuela de música. Según Jaime, esta acción supuso un revulsivo, ya que propició un cambio en la forma de estudiar música en la población, e hizo crecer a la banda como asociación. La banda de música es una de las entidades culturales más importantes de la localidad:

Es una entidad que creo que participa mucho en la vida festiva del pueblo. Claro, hacen fiestas, procesiones, hacen un acto de no sé qué y siempre está presente. Entonces está muy vinculada, ya no sólo la banda, las personas de la banda, sino las familias de la banda. Porque claro, eso al final eres tú y la gente. Porque si los padres te llevan a aprender es porque tienen interés, $\mathrm{y}$ todo se relaciona, y eso es una cadena de gente.

En 1992 el ayuntamiento creó un Patronato de Cultura, debido a la necesidad de proteger el patrimonio histórico. Las tareas para la constitución del 
mismo recayeron, una vez más, en Jaime: redactó los estatutos, buscó a las personas que podrían estar interesadas en formar parte de la junta rectora, etc. Desde la corporación municipal se le dejaba hacer. El Patronato actuaba de forma muy independiente, y se estableció un plan de restauraciones y una programación cultural anual. Jaime ejercía un papel de liderazgo y gestión, pero también trabajaba a pie de calle:

Yo, al principio, me dedicaba más al trabajo de calle, porque lo que hacíamos, lo teníamos que hacer nosotros. Pues si hacíamos una exposición, a montarla nosotros. Si hacíamos una actuación musical, pues a montar las sillas. Lo hacíamos todo los del Patronato.

La implicación de Jaime en el Patronato era muy grande. Él fue el principal impulsor, y quería que la trayectoria de esta institución produjese un cambio en el pueblo a nivel cultural y de puesta en valor del patrimonio. De hecho, se emprendió un gran número de restauraciones durante aquellos años. Otra de las acciones en relación al patrimonio fue poner en marcha un programa de visitas guiadas a la iglesia, tal y como Jaime las hacía cuando era un niño. Con el paso del tiempo la puesta en valor del patrimonio generó una serie de necesidades de carácter técnico que condujeron hacia la contratación de personal más especializado en la materia por parte del ayuntamiento. Este hecho repercutió en el grado de implicación de las personas que formaban parte del Patronato de Cultura. Actualmente es un organismo de carácter únicamente consultivo.

También se involucró en la Mesa técnica del Programa de Extensión Universitaria de la Universitat Jaume I. Este programa tiene la singularidad de trabajar únicamente con municipios de menos de 5000 habitantes y de un modo muy directo, facilitando la participación de los agentes del territorio, y la toma de decisiones conjunta. Jaime se sintió muy vinculado a este foro, ya que se considera una persona muy preocupada por el futuro del mundo rural en el que él vive. Así, la Mesa técnica era un punto de encuentro, de reunión, de debate y de apoyo, que confrontaba con un mundo rural excesivamente individualizado, caracterizado por la poca unión entre poblaciones.

Gracias a su trayectoria Jaime entiende que los procesos de aprendizaje se dan a lo largo de toda la vida. Su implicación en el mundo asociativo le 
reporta una gran satisfacción a nivel personal. Se encuentra muy cómodo con lo que hace, sobre todo cuando puede ayudar a la gente. Cuando formaba parte de la asociación juvenil, disfrutaba gestionando las actividades que se programaban y viendo cómo la gente también lo hacía participando en las mismas. En cuanto a la banda, le gusta tocar porque lo hace para el pueblo, y porque se reconoce el trabajo de la agrupación en favor de la cultura local. Para Jaime es muy importante la convivencia y el buen ambiente que existe en esta última entidad. Lo que realmente le llena es «hacer para los demás»: aportar una parte de sí mismo a la mejora y al bienestar de la población.

A lo largo de su paso por las diversas asociaciones de las que ha formado parte, Jaime se ha formado como persona. Afirma que no sería él si no hubiese estado en esos lugares. Todas estas experiencias le han aportado un bagaje para su construcción de la realidad, para relacionarse socialmente, para entender a los demás, para ser y obrar de una determinada forma. Gracias a su vinculación al Programa de Extensión Universitaria, Jaime amplió su mirada sobre el desarrollo del mundo rural, especialmente desde un enfoque cultural, conoció otras realidades cercanas, contrastó su situación con otras, aprendió a solucionar problemas a través de las experiencias del resto de agentes, y contribuyó a crear una visión común sobre la realidad del mundo rural y sus necesidades:

Encontré una gente que en diferentes actividades y en diferentes opciones, porque se han integrado allí, todas tienen el mismo fin: mejorar la vida de los ciudadanos del mundo rural. Mejorar la calidad de vida integrada en todo: económica, cultural, de servicios, todo. Porque todo eso influye para que una persona decida vivir en el mundo rural, porque además de aceptar vivir en esa realidad de ese territorio, puede tener cada vez una serie de cosas que le hagan la vida más buena.

Mediante su papel en el Patronato de Cultura, Jaime pudo participar en procesos decisorios sobre la puesta en valor del patrimonio y la cultura locales, adquirió nuevas habilidades relacionadas con su gestión y, en definitiva, lo conoció y respetó todavía más, y entendió la necesidad de legarlo a las generaciones futuras.

Por lo que respecta al acceso a la cultura, Jaime se siente condicionado por el hecho de vivir en un pueblo. A pesar de que hoy en día Internet facilita 
este acceso, a lo largo de su vida las circunstancias no han sido las mismas. Para ver una obra de teatro, o asistir a un concierto de música, era necesario desplazarse a ciudades más grandes, y contar con un vehículo. Esto, considera, repercute en el interés de los pueblos por las actividades culturales: no son accesibles ni cercanas. El único equipamiento que existió en la población durante muchos años fue la agencia de lectura.

En cuanto a la participación en la vida cultural del conjunto de los habitantes de su población, Jaime considera que, a pesar de la existencia de un gran número de entidades, la realidad asociativa se caracteriza por la parcelación. Cada colectivo atiende únicamente a sus propios intereses y no a un bien general. Por otro lado, la implicación en las mismas suele ser desigual. Las personas que se encargan de la gestión son pocas, y muchas veces las mismas en diversas entidades.

Para finalizar, Jaime considera que los pueblos están muy alejados, en materia de cultura, respecto de las ciudades. Es crítico con las administraciones y con los políticos, que buscan la mayor rentabilidad de las inversiones - el mayor beneficio para el mayor número de personas-, y también rédito electoral, lo cual incide en las desigualdades entre un ámbito territorial y el otro.

\section{Discusión y conclusiones}

En cuanto a los objetivos propuestos inicialmente, el análisis de los resultados apunta a que los motivos por los que se participa en la vida cultural desde los posicionamientos más activos, se hallan en el alineamiento con los conceptos de ciudadanía activa, bien común y compromiso. En cuanto a los aprendizajes que se derivan de la participación destacan el saber ser y saber convivir, y el hecho de ganar amplitud de mirada respecto a la diversidad cultural.

A través de la participación en la vida cultural, Jaime aprende a situarse en el mundo y en su contexto territorial local; en ese lugar que él define como mundo rural. Un entorno con el que se muestra muy identificado pero también, si no discriminado, sí en situación de desigualdad respecto a otras zonas más 
densamente pobladas. Esto condiciona inevitablemente el acceso a la cultura (Shaheed, 2010), hasta el punto de ser ésta calificada como algo lejano, propia de otros contextos más urbanos.

Otra cuestión es el refuerzo del sentimiento de vinculación con la comunidad local, a través del establecimiento de relaciones con los conocidos. Se trata aquí de aprender a convivir (Delors, 1996). Estas relaciones se dan, muy especialmente, con las personas con las que comparte los espacios de socialización secundaria: los otros miembros de las asociaciones en las que se involucra. Estas personas se convierten en amistades, a las que se llega a considerar incluso parte de una gran familia, como en el caso de la banda de música.

La creación de estos vínculos es indispensable en los contextos de aprendizaje y participación en la vida cultural. Al mismo tiempo, son fundamentales para entender la historia de vida de Jaime, en la que hace mención de manera reiterada a las relaciones que ha mantenido con mucha gente y en todos los ámbitos: en las asociaciones, en el Patronato de Cultura, en el Programa de Extensión Universitaria, y en el ayuntamiento.

Gracias a su trayectoria vital, Jaime acaba teniendo una visión muy amplia del concepto de cultura, no sólo como un producto sino también como un proceso inherente a la propia existencia (Grupo de Friburgo, 2007). Un proceso mediante el que las personas y las comunidades locales pueden desarrollarse y mejorar sus condiciones de vida.

La historia de Jaime nos permite observar la vocación por el trabajo comunitario. A menudo comenta que la organización de actividades, o la participación en la banda de música, le llenan. Una sensación expresada con sencillez, y que nos remite a la satisfacción personal de quien, viendo reconocido su trabajo, no pretende sonsacar un beneficio individual, sino aportar su grano de arena al crecimiento de toda la comunidad. Esta sensación que, para Jaime, es el alimento del espíritu, nos dirige hacia el concepto de ciudadanía activa y de participación en la vida pública para el bien común (Gadea, 2007).

Se transmite así un compromiso ético de Jaime en el ejercicio de la libertad a través de su acción, partiendo de aquello que lo motiva a participar, y de las consecuencias y finalidades de su participación desde unos principios 
de justicia y responsabilidad. Una libertad que nos habla, en términos identitarios, de su deseo de ser y que implica el deseo de ser de los otros. Jaime lo dice en el mismo relato: «no sería yo si no estuviese en esos lugares». Desde este posicionamiento ético es necesario plantearse más la identidad en términos de lo que podemos hacer los unos por los otros, y no solamente preguntándonos quiénes somos (Kreusburg, 2011).

La participación activa se manifiesta como un fenómeno necesario en los contextos territoriales de los que trata el estudio. En numerosas ocasiones, son los mismos vecinos los que se encargan de muchas tareas relacionadas con la producción de actividades culturales, entre otras cuestiones.

Bonet (2005) ha argumentado que los procesos de participación en la vida cultural se dan más fácilmente en las comunidades pequeñas y relativamente homogéneas. Sin embargo, la historia de Jaime transmite que la participación activa no es tan sencilla. Su caso es una excepción dentro de su contexto. Existe una gran dificultad para encontrar personas que se impliquen activamente en los procesos de participación activa en la vida cultural. Si además esta participación implica gestión, siempre acaban encontrándose las mismas personas en diferentes espacios. La consecuencia para estos participantes activos suele ser el abandono de las responsabilidades que asumen, debido al agotamiento mental al que se ven sometidos, a las críticas que reciben por parte de los participantes pasivos, y a la falta de reconocimiento de su trabajo desinteresado.

No se participa porque los fines de la participación en la vida cultural no son tangibles. Es decir, no hay un objetivo claro, o inmediato, más allá de la organización de una actividad o de la restauración de un edificio. Los ámbitos en los que, en la historia de Jaime, se consigue la participación de más gente son aquellos en los que las personas se muestran más cooperativas e iguales desde el punto de vista de la distribución de tareas. Por ejemplo, en la banda de música, donde todas las personas que forman parte de la entidad son músicos. También funcionan aquellos espacios donde la injerencia política es mínima. En el caso de la historia de Jaime, los primeros años de vida del Patronato de Cultura en los que la implicación de la corporación municipal fue testimonial, fueron los más intensos. 
Esta última cuestión conduce a pensar cuál ha de ser el papel institucional respecto a la participación en la vida cultural, y a plantearse si la institucionalización de la participación está matando este tipo de iniciativas cívicas. En este sentido Rathier (2012), comenta la importancia de hablar en términos de democracia en su sentido más radical, y no en su versión edulcorada, que es la de la democratización de la cultura. La participación deseable, de este modo, no debería entenderse como el aumento del número de asistentes a un evento cultural.

Las democracias modernas han institucionalizado la cultura como mecanismo de identificación social con la nación o con el Estado. La lucha social de hoy (Fernández, 2000) es por los derechos culturales. El trasfondo de esta situación viene dado por unos estados-nación que, a través de sus comunidades imaginadas, son incapaces de responder por sí solos a la construcción cultural de las sociedades. La lucha por los derechos culturales implica así un reencuentro con las comunidades reales en las que, desde lo local, los individuos se conocen y se reconocen mutuamente, establecen relaciones mediante las que se sienten cohesionados, y comparten unas mismas identidades culturales más sólidas.

\section{Referencias}

AChugar, H. (2003). «Derechos culturales: ¿una nueva frontera de las políticas públicas para la cultura?», Pensar Iberoamérica, núm. 4. Recuperado de http://www.oei.es/historico/pensariberoamerica/ric04a04.htm

Arroyo, L. M. (2006). «Los derechos culturales como derechos en desarro1lo: una aproximación». Nuevas políticas públicas. Anuario multidisciplinar para la modernización de las Administraciones Públicas, núm. 2, pp. 262-283.

Bolívar, A. (2002). «¿De nobis ipsis silemus?: Epistemología de la investigación biográfico-narrativa en educación». Revista Electrónica de Investigación Educativa, 4 (1), pp. 1-26. Consultado el 19/06/2016 en http://redie.uabc.mx/vol4nol/contenido-bolivar.html

Bolívar, A., Domingo, J. I Fernández, M. (2001). La investigación biográfico-narrativa en educación. Enfoque y metodología. Madrid: La Muralla. 
Bonet, L. (2005). «Factores condicionantes de la participación cultural». Boletín GC: Gestión Cultural. Participación ciudadana. Núm. 11, 1-8.

Delors, J. (1996). La educación encierra un tesoro. Informe a la UNESCO de la Comisión Internacional sobre la educación para el siglo XXI. Madrid: Santillana-UNESCO.

Fernández, L. A. (2000). «La lucha social hoy es por los derechos culturales». Entrevista a Alain Touraine. Recuperado de http://www.culturalrights.net/descargas/drets culturals136.pdf

Francés, F. J., García, J. T. i Santacreu, O. A. (2007). Modelos participativos e innovación democrática local en los municipios valencianos. IX Congreso Español de Sociología. Recuperado de http://rua.ua.es/ dspace/handle/10045/2235

GADEA, E. (2007). Las políticas de participación ciudadana: nuevas formas de relación entre la administración pública y la ciudadanía. El caso de la ciudad de Valencia y su área metropolitana. València: Universitat de València.

Grupo de Friburgo (2007). Los derechos culturales. Declaración de Friburgo. Recuperado de http://www.culturalrights.net/descargas/drets culturals239.pdf

Kreusburg, R. (2011). «Cuestiones éticas en torno a la investigación sobre y con historias de vida». En Hernández, F., SAncho, J. M. i RIvas, J. I. (coords.). Historias de vida en educación. Biografías en contexto. Barcelona: Universitat de Barcelona.

LAAKsonen, A. (2006). La cultura comprometida. Los derechos y deberes culturales. Periférica. Revista para el análisis de la cultura y el territorio, núm. 7, pp. 105-119.

Leite, A. E. (2011). «Preocupaciones epistemológicas y metodológicas en torno a la construcción de historias de vida». En Hernández, F., SAncho, J. M. i Rivas, J. I. (coords.). Historias de vida en educación. Biografías en contexto. Barcelona: Universitat de Barcelona, pp. 42-46.

Martinell, A. I López, T. (2008). Políticas culturales y gestión cultural. Organum sobre los conceptos clave de la práctica profesional. Girona: Documenta Universitaria.

Merino, J. V. (2011). «La educación a lo largo de la vida. Un proceso inherente a la naturaleza humana, necesidad y demanda social»; en http://quadernsanimacio.net; no 14, julio de 2011.

Moriña, A. (2010). «Vulnerables al silencio. Historias escolares de jóvenes con discapacidad». Revista de Educación, 353, pp. 667-690. 
Ortega, J. (2005). «La educación a lo largo de la vida: La educación social, la educación escolar, la educación continua... todas son educaciones formales». Revista de Educación, 338, pp. 167-175.

Pascual, J., Dragojević, S. I Dietachmair, P. (2007). Guía para la participación ciudadana en el desarrollo de políticas culturales para ciudades europeas. European Cultural Foundation. Recuperado de http://www.policiesforculture.org/administration/upload/Guia participation_ciudadana_ESP_web.pdf

Pindado, F., Rebollo, O. i Martí, J. (2002). «Eines per a la participació ciutadana: bases, mètodes i tècniques». Papers de participació ciutadana, núm. 6. Barcelona: Diputació de Barcelona.

Ramdsen, P. (1992). Learning to Teach in Higher Education. Londres: Routledge.

Rathier, J. P. (2012). "Attention auxi voisins. Pour une éthique des arts mitoyens». L'observatoire: la revue des politiques culturelles, 40 , pp. 25-29.

SÁEz, J.P. (2012). «De la participation». L'observatoire: la revue des politiques culturelles. Núm. 40, pp. 1-2.

Segarra, T. (2013) La participació en la vida cultural i els aprenentatges informals. TFM Inédito. Máster en Gestión Cultural, itinerario de investigación, Universitat Oberta de Catalunya.

ShaheEd, F. (2010). «Informe de la experta independiente en la esfera de los derechos culturales, Sra. Farida Shaheed, presentado de conformidad con la resolución 10/23 del Consejo de Derechos Humanos». En Maraña, M. (coord.). Derechos culturales. Documentos básicos de Naciones Unidas. Bilbao: UNESCo Etxea.

UIS (2012). Measuring Cultural Participation. Montreal: UNESCO, Institute for Statistics. 